\title{
Development: Crossing the Bridge Pondering Socio-Economic and Techno-Science
}

Nikolaos Karanasios ${ }^{*}$, Antje Tandetzky*, Antonella Reitano"*** Marco Fazio****, Elena Stavrova"*****

\section{Abstract}

Applied science, society needs and economy development are three main pillars of the technology progress nowadays. As they are quite independent of each other they have their own path for advancing. Nevertheless, science, society and economy should bring the world in the Future together.

It is stated that there is a strong need for pondering these advancing sciences, because they affect one another and so they may increase their effectiveness.

Several techno-science empirical observations seem to support the hypothesis that interaction and reciprocal influence is necessary with social and economic sciences.

Keywords: Adaptation, Innovation, Research, Sci Tech, Scientific, Technical, Technology, Economic Sociology

JEL: D24, M21, 032

\section{Introduction}

Economic progress can be attained

Eby different means. Scientific and technological developments have proven to be exceptionally successful in offering the economy a remarkable improvement and raising standards concerning all areas of human life. However, a gap between society and the economy came about that is broadened through technical and scientific progress. The fear of the future and technology-related anxieties among some members of society have a long history and need to be addressed seriously. Socio-economic sciences have a relevant role in providing orientation in our dynamically changing time, which is driven through the acceleration of technological progress.

Possibilities for bridging the gap between social science and techno science will be presented based on current technological developments. Drones, Artificial Intelligence (Al), quantum computing and nanotechnology engineering, among others, will serve as empirical references of contemporary technological trends. Their benefits as well as the challenges and the threat they may imply will be illustrated. Furthermore, the responsibility and overlap of techno-science and the socio-economic science will be identified. Subsequently, a proposal towards the desirable objective of socio-economic science within the new era of technological development will be made. After all, the need

\footnotetext{
* Assistant Professor of Business Administration, International Hellenic University, Serres, Greece.

** Department of Business Administration, DHBW Mannheim, Germany.

*** prof. Ing., Dipartimento di scienze aziendali e giuridiche, Università della Calabria.

${ }^{* * * *}$ Prof. Ing. Dipartimento di scienze aziendali e giuridiche, Università della Calabria.

***** Assoc.Prof. South-West University "Neofit Rilsky".
} 


\section{Articles}

for assistance and orientation through social science may have never been greater.

The concept of technology can be interpreted in different ways. To avoid talking at cross-purposes the assumption is made that technology is the result of the development by engineers and practical use by society of the "products of engineering design: devices, systems, procedures and methods" (Brey, 2018). Hence, this definition will be used for a shared understanding of technology.

We live in an unprecedented era. More than ever before, the $21^{\text {st }}$ century will see drastic changes due to scientific and technological development. In addition, our epoch will be known for the fourth industrial revolution, which will be explained later on. The biggest challenge lies within the capability of people to keep up with the speed of technological progress and the implied alterations for society. Astrophysicist Carl Sagan summarized the current situation as follows:

\section{"We have also arranged things so that almost no one understands science and technology. This is a prescription for disaster. We might get away with it for a while, but sooner or later this combustible mixture of ignorance and power is going to blow up in our faces. (Sagan \& Druyan, 1997)"}

The prospects for technological development in the coming decades will be analyzed. It will be highlighted that people tend to make wrong assumptions about the applicability of a new technology, product or service when it is first invented or presented to the public.

As for the method applied to this paper, the following steps have been identified. The first step was literature review concerning similar topics and complementary information of both techno-science and socio-economic science. The second step was the observation
Development: Crossing the Bridge Pondering

Socio-Economic and Techno-Science

of empirical evidence of the enterprises, the research published by engineers. The final step was the identification of the connection between technological progress and its social impact.

\section{Technological progress and regulation}

New products and services often face social barriers when first being introduced to the public. A lack of knowledge about the mode of operation may be one of the main reasons for that. Consequently, technology outruns society's capability to keep up with the new development. One example for fear of the unknown, backed by the ignorance about the technology behind the new product are autonomous, remote-controlled drones, which were first rejected by the public. Commercial drone flight has many potential applications for businesses, especially in combination with aerial photography, as is the agricultural sector, for instance. The drone market, like other emerging technologies (driverless vehicles), faces many issues, many of a regulatory nature. This is because the drone industry is overall (relatively speaking) still in its infancy years. Operational questions are partly answered in certain countries, yet there is no international standard for drone flights. Like other emerging technologies, the drone industry lacks any international standards. New mechanisms need to be established to face the challenges that were unheard of before. Technology threatens the old way of living. Former habits lose their relevance. Nevertheless, there are tendencies among those scared of progress to halt new inventions, e.g. cars were first not allowed to go faster than horses could run. This exemplifies the characteristic conduct of people who are unable to cope with a new situation and accordingly show resistance to change.

Inventors are interested in shortening the time span between the development of a new product or service and the general acceptance of the said technology by the public, namely 


\section{Articles}

the consumers. Oftentimes new regulations are necessary in order to assure society of the benefits and harmlessness of a new technology. At this point corporations and entrepreneurs alike find themselves confronted with a void bequeathed by the institutions that cannot keep up with the speed of technological progress. To smoothly introduce a new technology, providers themselves should recognize their responsibility for and establish the conditions needed to create a successful network incorporating society and institutions. If a business fails to establish trust in their technology, its future prospect is not optimistic.

The emerging markets are an example of a business environment that requires a lot of contribution of the technology providers. In established markets, institutional support can be found in terms of functioning courts, a secure banking system, reliable credit rating agencies, universities providing businesses with a highly qualified workforce, etc. These elements of institutional infrastructure cannot be taken for granted in developing markets. Businesses are well advised to liaise with institutions to set up the regulatory structure needed for their business model to thrive and for society to accept the new products or services provided. In addition, corporate business will benefit from realizing and implementing the idea that they are more successful if they do not limit their operating range to the boundaries of their company but recognize the potential that lies in becoming a leader beyond the premises of their enterprise (Khanna, 2018).

\section{Technology in a good society}

Technology influences society and is reversely shaped by society. The development achieved through technological progress has the potential to contribute to a society. Among other things, technology can affect our social framework, perceptions, skills and behavior.

The concept of technological neutrality assumes that the benefit or harm of a product depends on the use or in fact on the user, not on the product itself. This notion is debatable as modern technological inventions are most often only suitable for a very particular purpose. This confines the potential effect on society. At the same time, it allows identifying correlations between the product and its impact on society due to the few situations it is used in.

The way technology influences the social environment is either through affordances or through constraints (Brey, 2018). This suggests that the result is either enabled or prevented from happening. The following shift of our understanding and sensitivity is the actual impact of technology. The alteration may happen on a micro-, meso- or macrolevel, referring to a transformation on either an individual-, group- or societal level. With the objective of determining the role of technology in society, the macro-level is of distinctive interest. It is indisputable that new technologies will offer advantages to many while closing out those who do not possess the requirements to utilize a new product or service. Furthermore, the introduction of new technology oftentimes implicates the demand for improved conditions to facilitate the use of the new development. This way technology has yet more influence on the conditions of the social environment. In addition, social arrangements are modified by technology. The augmentation in the speed of globalization is an example of the facilitation of social structures through technological products. The expansion of global e-commerce serves as a distinct illustration of that.

Technologies are being developed in such a way that they contribute to the goodness of society, not to the decrease in the quality of 


\section{Articles}

the citizen's life. Social science can support techno science by clarifying what values are intrinsic and therefore fundamental for a society's quality. Five key values are suggested that set up a good society. Those include the well-being of citizens, justice, freedom, democracy and sustainability (Brey, 2018). These rather abstract virtues leave a lot of space for individual interpretation. Yet they set up the basis, while numerous instrumental values can be added to achieve the overall objective of creating a good society.

The European Union ratified the Charter of Fundamental Rights of the European Union (CFR) in 2000. This document is a record of the basic rights of EU citizens, which are dignity, freedom, equality, solidarity, citizen's rights and justice (European Union, 2000). These values support and complement the standards suggested before.

Technology either adds to these fundamental values or diminishes them and hence is capable of moving a society towards or away from attaining its values. This depends highly on the design of technology. The development of technology should incorporate the core values of a good society into the process of designing the innovation. In addition, the embedding of new technology should be closely monitored. The acceptance of new technology among the public could be enhanced by combining the implementation of new developments with altered or newly introduced laws and regulations that will help establish the innovation (Brey, 2018), even though overregulation can possibly curb progress.

In brief, technology is more than the tools used to process a task. In fact, technology has the potential to alter our values and change our thinking both on an individual as well as on a societal level. The assessment of a new technology always implies the
Development: Crossing the Bridge Pondering

Socio-Economic and Techno-Science

assessment of our culture, the state of our society (Coeckelbergh, 2016).

\section{Artificial Intelligence and the fourth industrial revolution}

The fourth industrial revolution will be the coming era that will be exhibited through the further development of Artificial Intelligence (Al), robotization and automation. Makridakis (2017) examines the possible outcome of the next twenty years regarding $\mathrm{Al}$ technology and whether it may achieve or draw near human intelligence. The digital revolution, which emphasized the power of computers, is ubiquitous in most aspects of our daily lives, including the workplace. The upcoming Al revolution, which highlights the power of the human brain, will have an even bigger impact.

The biggest challenge for research and all those with a future-oriented belief lies in making the most adequate predictions towards the actual impact that $\mathrm{Al}$ will eventually obtain. Inventions related to Al will without any doubt change society earlier than we currently expect. The past showed that simply extrapolating the development from the past leads to wrong assumptions about the future. The technological development cannot be defined as linear. It is evident that the time passing between development and commercial success continues to decrease. This is why the Al revolution needs to be estimated as greater than anything humanity has experienced so far. The reason that $\mathrm{Al}$ is not just noticeable but clearly outstanding compared to classical computers is its ability to demonstrate actual learning, which goes beyond the execution of preset tasks. A recent example for the technological progress was the victory of $\mathrm{Al}$, namely a computer program called AlphaGO over the world's best human GO player in 2016 (GO is a board game, similar to chess). Deep learning algorithms have just started their success. 


\section{Articles}

It is too early to determine whether the future will therefore turn out to be utopian or dystopian. The uncertainty challenges not only researchers and developers but also the public. It may sound like a platitude to declare that the benefits of $\mathrm{Al}$ should be exploited while at the same time trying to avoid potential harm. There will be breakthroughs just within the next two decades that we cannot imagine yet.

Makridakis distinguishes four different scenarios for the upcoming $\mathrm{Al}$ revolution. The first group is made up by optimists who assume that machines may soon be smarter than humans are. The pessimists expect the development of $\mathrm{Al}$ to end in dystopia. The pragmatists do not see $\mathrm{Al}$ as a threat, but actually believe that it will remain within human control. The doubters embrace the thought that human creativity can never be captured in form of algorithms.

We are yet to find out how Al will change the management and the sales strategies of companies. In addition, it is expected that unemployment could increase drastically due to the effective exploitation of new technology on hand. At this point social sciences should step in and give advice and guidance away from the employment and labor-centric worldview and towards a more social and community-centered concept of the world. Moreover, social science can promote awareness about how information technology supports the societal value of justice. For the reason that in the information age we live in, the worth of information rose from feature to necessity.

One thread contained in any technology used in enterprises is the risk of misuse and consequently fraud. Al may have an adverse or hostile impact on corporations utilizing this innovation. Security issues may be the most dangerous menace among them. Standards and regulations on professional use of $\mathrm{Al}$ and other innovations such as robotics and block chain technology need to be developed soon (Nickerson, 2019). Besides, Al frequently fails to deliver what it is promising. One example for that would be the Boeing software failure in 2019.

Al holds the promise of enhancing productivity even more than the advancements that have been accomplished through the digital revolution already. Humanity was never able to halt progress on a large scale. The danger lies within the increase of inequality, not necessarily the fact that people experience unemployment. After all, it seems unlikely that this time should be different. New technologies are necessary to tackle the challenges our world is facing in the $21^{\text {st }}$ century, artificial intelligence might be the relief needed.

\section{Quantum computing}

Quantum computing is one of many practical applications derived from the principles of quantum mechanics, which studies the behavior of atoms and develops usages to our benefit.

Quantum technology (including other fields of application such as quantum cryptography, quantum metrology or quantum simulation) has the prospect to ignite a new technological era and change our understanding of how we process information completely. The further development of quantum technology into quantum computing may provide advantages for both society and economy. Quantum technology is the basis for a new generation of computers and will revolutionize the way we think of computing and data processing. Quantum computers will have the ability to use optimized algorithms and speed up calculations on an exceptional scale. This implies opportunities for academia, public institutions and corporations alike.

The computer, as we know it and use it in 2019, still follows the same principles as we 


\section{Articles}

know them since von-Neumann's architecture, based in 1945, with the processor as the main element of the computer. The architecture has not been altered greatly, the commands still work sequentially, meaning one after another, after having been transformed into binary steps. That means all data are sampled and the inapt solutions will be eliminated. The quantum computer works in the following way: it does not compute sequentially, instead the information is processed in a parallel manner, meaning at the same time (Jaeger, 2018), because the replacement of quartz drastically increases the speed. In order to simplify the notion of how the quantum computer works, it is sometimes predicated that a quantum computer can process many operations at the same time. Actually, it would be more precise to state that the quantum computer has the ability to find the correct solution out of many potential solutions. The quantum computer entangles the superposition of the input value with the task. In this way, the solution with the highest probability of being correct will be detected (Brands, 2011).

Today's computer chips are able to process one billion operations per second. Microchips based on semi-conductors made this development possible (Jaeger, 2018). Interestingly enough even this classical computing has quantum physics as a base as the movement of the electrons on the semiconductor follow the rules of quantum mechanics (Waldrop, 2016).

Several private companies and universities from around the globe approach quantum computing from different technological positions. Research is led by institutions in the United States, Canada and China. One challenge that the potential applicants of quantum computing face is that so far there is no functioning and fully developed quantum computer in commercial use through a private
Development: Crossing the Bridge Pondering

Socio-Economic and Techno-Science

company or owned by an academic institution to test its possible usage.

The coming years will show if the capability of quantum computing can be brought to a larger scale. So far the expected revolution is still in its fledgling stages. Pessimists may argue that quantum computing will only serve niche markets while those more enthusiastic for upcoming progress in that research field see a paradigm shift ahead (Waldrop, 2016).

\section{Nanotechnology}

Nanotechnology refers to the area of science that examines matter on a small scale, in the dimension of atoms and molecules. A nanoparticle is the smallest unit that is used to create nanostructures. The main idea is to create new materials by either joining or separating matter in the nano-scale. These nanostructures differ (in an unexpected way) from the initial nanoparticles used. The newly developed nanomaterials have plenty of applications. Among others, they are used in IT, the automobile industry, chemical industry, the pharmaceutical industry and the biotechnology sector. The food industry and electronics can be improved by nanotechnology as well. Although our electronics often carry 'micro' in their name as in microprocessor a switch to the expression 'nano' would be appropriate, considering the level of penetration of the area of electro technology by nanotechnology.

The medicine sector and therefore our health benefits the scientific research in nanotechnology, starting at the prevention of disease, crossing over to more in-depth diagnosis and improving therapeutical methods. In the area of pharmaceuticals, the technology is used in potent medication in nano-size.

On the other hand, nanoparticles may be a threat to human health. For that reason, risk management is necessary to identify and tackle the threats. It is crucial to understand 


\section{Articles}

that due to their size nanoparticles are easily absorbed into the human body. Nanoparticles may cause toxic reactions. This depends on the individual characteristics, e.g. the chemical composition of said particle. Respiratory toxicity is one way nanostructures can harm and cause damage.

The values of sustainability and wellbeing could be fiercely improved through the linkage of nanotechnology and renewable energies. Bio fuels and water purification system based on nanotechnology are being developed.

There are ethical implications to using a technology that may intentionally or unintentionally cause harm. Taking the Charter of Fundamental Rights of the EU as a guideline the proposed values, namely dignity, freedom, equality, solidarity, citizen's rights and justice need to be guaranteed to all citizens. A technology with undetermined outcome needs to be handled with ample responsibility.

If safe products and services can be created with nanotechnology they should be distributed to all who need it. A stable and safe society can be thus guaranteed. Moreover, the issue of dual use could be a concern and needs to be addressed conscientiously. Public safety must be a ubiquitous consideration of scientific research and techno science alike. Misuse (out of dishonesty or incautious behavior) of this potent technology has to be prevented by all means. The operating mode, purpose and application method of a product or service based on nanotechnology needs to be intelligible and coherent to the user. Furthermore, the efficient use of resources should be practiced not only during operation but also in the earlier, developmental stage of nanotechnology. In this way, sustainability objectives and environmental conservation can be enforced.

In brief, nanotechnology is talked about a lot because of the many applications it presents and the benefits concerning the protection of the environment through scientific research in this field. What is more, it is part of a technological revolution and will rather sooner than later transform society.

As with other scientific developments, the exact outcome cannot yet be evaluated precisely. There are techno-optimists with an overall favorable view towards nanotechnology. In turn, there are doubters and sceptics who point that toxic materials are used in the production of nanostructures and that industrial scale production of nanostructures is far-fetched. The manufacturing process is resource- and energy-intensive (Purohit, et al., 2017).

\section{Broken-window effect and waste crime}

The role of the police has shifted since the middle of the $20^{\text {th }}$ century from maintaining order towards fighting crime. Crime prevention can hardly be executed anymore, mostly due to limited police resources. Formerly, the police were in the position of watchmen and managed street life. They used to protect the citizens and the community they live in. Nowadays they act solely as crime fighters.

The broken-window theory comes into effect at this point. It indicates that if a broken window in a building is untended, soon all the other windows in the same building will be broken as well. It is a signal to the environment that nobody feels responsible for repairing the window and restore the former order. Referring to rundown neighborhoods this implies that the beggar on the street represents the first broken window in the row of many more to be destroyed subsequently. Drunks, addicts and muggers follow soon, only to be succeeded by burglars (Wilson \& Kelling, 1982).

This pattern can be applied to the issue of waste crime, too. It is a societal challenge, which is prominently linked, amongst other countries, to Italy. (Dell'Anno, et al., 2019) 


\section{Articles}

discovered that waste crimes are associated with disadvantaged communities. Waste crime is one of many illegal activities that cause a strong financial impact on the public and on the local municipalities. It turned out that a stricter environmental policy will not reduce the problem. What needs to be improved instead is the level of law enforcement. Furthermore, a low economic performance and a low education performance are linked to waste crime. These factors do not directly cause waste crime, but they are mediated by other concealed parameters such as general criminal behavior, environmental crime and the relevance of the Mafia in Italy. Waste crime turns out to yield high returns and constitutes a structural problem that needs to be solved primarily by strengthening judicial enforcement.

As with the other societal challenges mentioned already, a stronger cooperation between the authorities and the population needs to be established. In this way, citizens have the opportunity to report crimes and giving their neighborhoods the chance to 'repair the broken windows'. Moreover, with the increase of educational attainment, society has the chance to enhance their environment and add to the quality of life.

Techno-science, especially the area of environment engineering, developed modern environmental technology that allows for major improvement of waste treatment. Social sciences could assist in diminishing the resistance that prevent the construction of modern waste treatment facilities. For instance, they could develop a coping strategy for the affected communities and municipalities. In this way, the parties involved could learn how to tackle the social disorder and successfully carry out the projects concerning the protection of the environment. In addition, social sciences can raise awareness about how technology can contribute to the societal
Development: Crossing the Bridge Pondering

Socio-Economic and Techno-Science

virtue of sustainability. Technological products can induce after all sustainable behavior.

\section{Nuclear power energy and public concerns}

Another example of public opposition towards technology is nuclear power energy. This technology is not a recent invention, yet nuclear accidents anywhere in the world provoke intense anti-nuclear protests and strong adverse response from the public. Safety concerns rose after an accident in a nuclear power plant in Japan in March 2011. It was the cause for Germany and other countries to consider and implement a nuclear phase-out.

The perception of risks regarding nuclear energy among the public were studied by Budnitz, et al., (2018) The mixed feelings towards nuclear power which by some opponents is declared a potential public menace and needs to be taken more serious by decision makers in order to accomplish more tolerance towards this technology. Among other reasons, negative reactions towards nuclear energy derive of the lack of technological understanding of the procedure of using nuclear reactions to release nuclear energy. Furthermore, public rejection reflects the perception of not being in control over an action that implies possible harm. A technology that is rather difficult to comprehend remains abstract and intangible to the general public. The discrepancy between the risk assertions of the broad public compared to nuclear engineers is striking. The public opinion on the use of nuclear energy also differs widely between nations and varies between countries that do or do not utilize nuclear power technology. A fragile social atmosphere can contribute to public pushback of misunderstood technology. Civil and societal acceptance can be consolidated by establishing awareness of a sound nuclear 


\section{Articles}

safety culture. Highlighting the economic benefits of the use of nuclear power may also increase tolerance towards this technology.

The nuclear power industry needs to strengthen the safety culture within their premises through intensive staff training and, among other duties, create an atmosphere in which errors and problems can be discussed without the fear of being ostracized. Moreover, a strong and independent regulatory agency is necessary to successfully implement and maintain nuclear-power technology. Of course avoiding any horrifying accident is the target of all aforementioned ambitions.

Again, social sciences should assume the function of depleting the resistance against this misunderstood technology. One option would be to offer sound information to the general public regarding the processes inside nuclear power plants and the strict safety regulations that prevail in these facilities. Presumptions and murky rumors concerning the potential misuse of a nuclear power plant to produce nuclear weapons of mass destruction need to be diffused.

Another function for social science can be to illustrate how the societal value of well-being can be included into the design of (energy) infrastructure. The social impact needs to be assessed and analyzed to determine the effects on society for quality of life of the individual and society being involved and possibly altered.

\section{Scientific responsibility}

For numerous reasons, new technologies often raise hackles and therefore risk public refusal of progress. Innovation is prevalently thought of as a means of improving society and relieving humanity of former challenges. Yet one could argue that the developers are not as considerate towards the intended or unintended outcome of their inventions as it may be necessary. The question of the responsibility of the scientist arises at this point. Research that has dual use and implies the potential to do harm needs to be handled carefully. No epoch before the last century brought as much change (improvements as well as threats) to humanity due to development in the sciences of chemistry, physics and biology, as in engineering and IT. Research, performed in scientific manner, undoubtedly is the foundation for progress. In contrast to that, society places arguably unobtainable responsibility on scientists and researchers, expecting them to offer solutions for society's challenges. Yet frequently the public remains skeptical, even distrustful towards the results of technological and scientific progress. Scientists seek to serve the public good. Regrettably, they are confronted with the possible abuse or misuse of their newly developed technologies or discoveries, which may threaten public safety. One point of view is that scientific work implies the responsibility to warn of potential danger emerging from recent research. Generally, it lies within the nature of research that its outcome cannot be estimated beforehand. Techno-scientists face a dilemma as their work frequently generates the potential for dual use, meaning that it could lead to either improvement or harm. One proposal to deal with this challenge is the establishment of advisory boards on scientific responsibility. Researchers need support in order to identify potential risk comprised in their work. However, the call for more regulations should not be attended if the purpose of an invention is not yet distinguishable. Ideally, academic, and more specifically research institutions take a lead in this field and promote awareness for scientific responsibility. Societal and political activities may otherwise confine the freedom of research. Regardless, society as a whole, not only researchers should assume responsibility 


\section{Articles}

for keeping up ethical values related to dual use inventions (Herrlich, 2013).

\section{Behavioral economics and the knowledge society}

Behavioral economics can offer the tools for an analysis of human behavior in the context of an economic environment, but includes the social background on the individual and communal level, too.

Behavioral economics teach us that people avoid cognitive dissonances as much as possible. People long for consistence in their speech, actions and beliefs. This is because society regards consistency as valuable and highly relevant to enable civilized community life. Consistent behavior fosters everyday life. In addition, consistency facilitates decisionmaking. Among other objectives, the attention of behavioral economics is directed towards the reflection of human behavior and the act of decision-making. For that reason, the activities that lead to a result out of choosing between options are profoundly studied.

Due to the increased speed of technological and societal development, it gets harder to be consistent without relying too much on heuristics and biases. Heuristics are being used to reduce complexity and to speed up the process of forming an opinion (Chavaglia Neto, et al., 2019). Rising wealth inequality and the inability to cope with change in a speedy era makes people feel overwhelmed and challenges their world outlook as well as their self-image. Most of the issues the world is currently facing do not have a simple solution. For that reason, some people tend to withdraw themselves from this fast moving environment.

At the same time, the formation of the so called knowledge society inside the knowledge economy is coming about. With the rise of the knowledge economy and the development of the knowledge-based society, scientific and
Development: Crossing the Bridge Pondering

Socio-Economic and Techno-Science

technological progress became a study object itself. It can be claimed that there is a deficit in theoretical support for techno-scientific progress. The research processes need fast improvement to activate scientific research progress and accelerate the innovation development. There are potential synergetic effects that cannot be exploited appropriately due to the lack of fundamental methodology in techno-scientific research and development (Melnikas, 2018).

\section{Technology foresight and social sciences}

Technology foresight is the process of bringing together in partnership scientists, engineers, industrialists, government officials and others to identify areas of strategic research and the emerging technologies likely to yield the greatest economic and social benefit and which in the long term will sustain industrial competitiveness (Martin, 1995).

The United Nations Industrial Development Organization offers the following definition of technology foresight: "the process involved in systematically attempting to look into the longer-term future of science, technology, the economy and society with the aim of identifying the areas of strategic research and the emerging generic technologies likely to yield the greatest economic and social benefits". (United Nations Industrial Development Organization (UNIDO), 2007).

Smaller, cheaper, faster, and smarter, is what scientists are searching for and they are succeeding somehow (Karanassios, 2006.).

The effort to predict and influence the future marketable technology, is pretty much influenced by the group interests in this while they are investing in research, or address business investments by the banks, or public investments and incentives if they represent policy makers. Technological achievements and innovations, in many 


\section{Articles}

cases, are coming from business ideas whose market success attracts scientific researchers, for fundamental improvements and applied researchers (engineers) who will transfer these achievements into industrial products and / or services. Technological achievements, both as laboratory research outcomes and as market ready goods or services, are a response to a hypothesis that they satisfy a human need and so they are a certain success. This assumption, in the technological foresight sessions, ignores the socio-economic readiness of the supposed users and also the "lateral" concurrency of forces, namely aesthetics, expected social disturbances, alteration of education, management change, fashion, nutrition, tourism etc. Similarly, with the Technological research the socioeconomic one is struggling to forecast and in the same time influence the future. These sessions of the "task forces" would benefit very much of the participation of economists, business administration experts, performing arts representatives, artists and consumer association representatives. Such an increment of these task forces, it is argued that would end up in becoming an arena, instead of a foresight.

\section{Discussion}

The first signs of the need for synergies between technology and society appeared in 1985 as an intellectual exercise, to become formally expressed as Social Shaping of Technology (SST).

What we find is that often technology offers solutions that are well intended and in fact improve or even enrich our lives. Yet many of our issues are in fact of political, economic or social nature and therefore need political, economic or social solutions. This should not undermine the significance of technology and science, but highlight the need for finding solutions based on the source of many challenges. Despite the numerous potential benefits of techno science and scientific research, the scarcity of resources will be accelerated through the scale of industrial expansion of high technology areas with elevated levels of energy and resource consumption such as nanotechnology and artificial intelligence.

It is essential to (re)focus on the core values of society and offer guidance through socio economic science. Surprisingly, the fear among the public not just towards the speed of technological progress, but also towards the techno-scientific progress altogether, tends to increase in times of a developing economic setting. It might have appeared more plausible to expect anxiety in times of economic depression.

Three forms of concern can be detected. First, there is the concern that machines will substitute labor. Second, there is the concern towards the moral consequences linked to the techno-scientific development. Third, there is the counterpart of a concern regarding the potential stalling of progress (Mokyr, et al., 2015).

\section{Conclusion}

This paper presented reasons and examples for rejection of new technologies, which is commonly spotted and can be understood as a reason for deferral of progress. Both, techno science and socio economic science play a part in diminishing the refusal towards techno-scientific development and research displayed to the public. Cooperation and mutual agreement on the interrelations of these disciplines is indispensable to their development. Especially if the common yearning for public acceptance of the often misapprehended innovations and inventions is set as the joint objective.

Technology-based applied research, mainly conducted by engineers, is usually 


\section{Articles}

considered as granted the acceptance of new technological achievements, just because they solve problems and facilitate life, while socio-economic and cultural disciplines have a tendency to doubt about any new technology.

It seems to be necessary that Technology and Socio-economic sciences have to start synchronization.

\section{References}

Brands, G., 2011. Einführung in die Quanteninformatik. Quantenkryptografie, Teleportation und Quantencomputing. Berlin: s.n.

Brey, P., 2018. The strategic role of technology in a good society. Technology in Society, Issue 52, pp. 39-45.

Budnitz, R. J., Rogner, H.-H. \& Shihab-Eldin, A., 2018. Expansion of nuclear power technology to new countries. SMRs, safety culture issues, and the need for an improved safety regime. Energy Policy, Issue 119.

Chavaglia Neto, J., Filipe, J. A. \& Bento, C. A., 2019. Creativity and innovation: A contribution of behavioral economics. International Journal of Innovation Studies, Issue 3, pp. 12-21.

Coeckelbergh, M., 2016. Technology and the good society: A polemical essay on social ontology, political principles, and responsibility for technology. Technology in Society, Issue 52, pp. 4-9.

Dell'Anno, R., Pergolizzi, A., Pittiglio, R. \& Reganati, F., 2019. Waste crime in Italian Regions: A Structural Equation Approach. Socio-Economic Planning Sciences.

European Union, 2000. Charter of Fundamental Rights of the European Union. Official Journal of the European Communities.

Herrlich, P., 2013. The responsibility of the scientist. EMBO Reports, Issue 14, pp. 759-764. Jaeger, L., 2018. Die zweite Quantenrevolution. Vom Spuk im Mikrokosmos zu neuen Supertechnologien. Berlin: s.n.
Development: Crossing the Bridge Pondering

Socio-Economic and Techno-Science

Karanassios, V., 2006.. Inventing the future of ICP-AES and ICP-MS. Plenary Lecture, Central Canada Spectroscopy meeting. Toronto, Ontario, s.n.

Khanna, T., 2018. When technology gets ahead of society. Harvard Business Review, Issue 5, pp. 86-95.

Makridakis, S., 2017. The forthcoming Artificial Intelligence (Al) revolution: Its impact on society and firms. Futures, Issue 90.

Martin, B., 1995. Technology foresight 6: A review of recent overseas programmes. s.l.:s.n.

Melnikas, B., 2018. The knowledge economy and the activation of scientific and technological progress: contemporary challenges. EKONOMIKA, Issue 97, pp. 7-23.

Mokyr, J., Vickers, C. \& Ziebarth, N. L., 2015. The history of technological anxiety and the future of economic growth: Is this time different?. Journal of Economic Perspectives, 03, pp. 3150.

Nickerson, M. A., 2019. Fraud in a world of advanced technologies. The possibilities are (unfortunately) endless. The CPA Journal, June, pp. 28-34.

Purohit, R. et al., 2017. Social, Environmental and Ethical Impacts of Nanotechnology. Materials Today: Proceedings, Issue 4, pp. 54615467.

Sagan, C. \& Druyan, A., 1997. The DemonHaunted World: Science as a Candle in the Dark. In: New York: Random House, p. 26.

United Nations Industrial Development Organization (UNIDO), 2007. Technology Foresight. s.l.:s.n.

Waldrop, M. M., 2016. More than Moore. The chips are down for Moore's law. Nature, 7589(530), pp. 144-147.

Wilson, J. Q. \& Kelling, G. E., 1982. Broken Windows. The police and neighborhood safety. The Atlantic, Issue 3. 